\title{
ANDMEID EESTI MAGEVETE KARPVÄHILISTE (OSTRACODA) FAUNA KOHTA
}

\author{
A. JARVEKULG, \\ bioloogiateaduste kandidaat
}

Eesti magevete karpvähiliste fauna on jäänud kuni käesoleva ajani peaaegu täielikult uurimata. Rohkem kui sajand tagasi ilmunud S. Fischeri $\left(1854^{1}\right)$ klassikalises uurimuses märgitakse 16 liigi ostrakoodide leidmist Keila-Joa ümbruse veekogudest, kusjuures mōnda neist kirjeldatakse esmakordselt. Nimetatud 16 liigist on läinud korda dešifreerida 15 (peale töös uuena kirjeldatud liigi Cypris scutigera). Lisaks Fischeri tööle on Eesti magevete karpvähiliste kohta kirjandusest teada ainult paar lühimärkust (Eichwald, 1852; Schneider, 1908).

Käesoleva artikli materjaliks on 350 ostrakoodide proovi 290-st mitmesugusest Eesti veekogust, mis on kogutud ja läbi töötatud 1956. a. maist kuni 1958. a. märtsini. Suhteliselt pōhjalikult on uuritud mitmesuguseid väikeveekogusid ja järvede litoraali, kuna vàhe on materjali jōgede-ojade ja osalt ka allikaveekogude kohta.

Autori poolt seni määratud materjali alusel koostatud Eesti magevete ostrakoodide esialgne nimestik sisaldab 50 liiki. Arvates juurde kolm Fischeri (1. c.) töös esitatud, kuid autori poolt seni leidmata liiki - Eucypris hirsuta (Fischer), Eucypris pigra (Fischer) ja Stenocypria fischeri (Lilljeborg) - ulatub Eesti magevetes seni kindlakstehtud ostrakoodiliikide arv 53-ni. Edasised uurimused peaksid loetelu täiendama veel ligikaudu paarikümne liigi vōrra.

Tärnikesega on alljärgnevas nimestikus tähistatud uued liigid Eesti faunale, kahe tärnikesega - uued liigid Nõukogude Liidu faunale.

\section{Cypridae}

*1. Ilyocypris gibba (Ramdohr) 1808. 우.

Haruldane, püütud väheste isenditena mudase pōhjaga väikeveekogudest. Leiukohad: Täätsi lähedalt (Orissaare raj.), 20. VII 1956; Saarepere küla (Türi raj.), 14. IX 1957.

\section{Ilyocypris biplicata (Koch) 1838. 우 우.}

Harva esinev liik, konstateeritud taimestikuga mudase põhjaga temporaarseis veekogudes. Leiukohad: Avaste küla (Pärnu-Jaagupi raj.), 28. V 1958; Saarepere küla, 14. IX 1957.

\section{*3. Ilyocypris decipiens Masi 1906. $\hat{o} \hat{o}$, 우. 우}

Võrdlemisi haruldane, meil leitud järvede mudase, liivase ja paese põhjaga litoraalist ja profundaalist. Arvukus enamasti väike. Leiukohad: Olemiste järv, 5. ja 6. IX 1957; Pikkjärv (569)² (Jõgeva raj.), 25. VI 1957; Saadjärv (Jôgeva ja Tartu raj.), 17. I 1958.

\footnotetext{
1 Aratrükk sellest tööst kannab aastaarvu 1851.

2 Järve number Riikoja (1934) järgi.
} 
*4. Notodromas monacha (O. F. Müller) 1776. $\hat{o} \hat{\delta}, \uparrow \circ$.

Väga sage ja enamasti arvukas liik. Ubikvist: elutseb väga mitmesuguse iseloomuga temporaarseis ja permanentseis väikeveekogudes, järvede litoraalis, jõgede ripaalis, allikaveekogudes, samuti riimvees. Leitud ka võrdlemisi tugevasti reostatud veest (Jägala jõgi Tallinn-Leningradi maantee lähedal, 21. IX 1956). Tegutsedes peamiselt vee pindkiles, esineb ainult suveperioodil (mai lõpust oktoobri lōpuni). Rohkem kui 100 leiukohta; levinud üle kogu territooriumi, kaasa arvatud suuremad saared - Saaremaa, Hiiumaa, Vormsi.

\section{Cyprois marginata (Straus) 1821 (= Cypris dispar}

Fischer 1854). 소 하, 우 우.

Keskmise sagedusega, enamasti arvukas liik. Konstateeritud meil ainult taimestikurikastes temporaarsetes veekogudes, valdavalt soistel aladel. Leiukohad: Elistvere asundus ja Äksi (Jôgeva raj.), 26. X 1957; Tuhu soo lääneserv (Lihula raj.), 28. V 1957; Langenurme lähedalt (Pärnu-Jaagupi raj.), 28. V 1957; Emajõe luht Ropka lähedal (Tartu raj.), 13. VIII 1956; Saarepere küla, 23._-29. VI 1956 ja 14. IX 1957 (5 leiukohta); Viljandi linna idaserva lähedalt, 29. VI 1956; Sinialliku lähedalt (Viljandi raj.), 30. VI 1956; Pabra järve lähedalt (Vastseliina raj.), 13. VII 1957.

\section{Cypris pubera O. F. Müller 1776. 우.}

Sage ja enamasti arvukas liik, tihti massiline. Eelistab elutseda nii temporaarseis kui ka permanentseis väikeveekogudes. Leitud ka limno- ja helokreensetest allikaveekogudest ning harva järvede litoraalist (Kahala järv, Harju raj., 15. VI 1957; Lahepera järv, Kallaste raj., 26. VI 1957). Juhuslikuna konstateeritud ojas (Veskioja, Türi raj., 11. VII 1956). Valdavalt kevadsuvine vorm, üksikutel juhtudel aga esineb kuni hilissügiseni (viimane leid 31. X). Rohkem kui 40 leiukohta; levinud üle kogu mandriala, leitud ka Saaremaalt.

\section{Eucypris crassa (O. F. Müller) 1785 (= Cypris dromedarius Fischer 1854). 우오.}

Võrdlemisi sage liik, arvukus keskmine. Meil leitud ainult taimestikurikastest lompidest, mis peale ühe on temporaarsed. Kevadsuvine monotsükliline vorm. Leiukohad: Vellavere küla (Elva raj.), 10. VI 1956; Tähtvere metsa lounaserv, 3. VI 1956; Variku, 2., 9. ja 22. V 1957 (2 leiukohta) ja Luutsna jõe luht, 5. V 1957* (kõik Tartu raj.); Saarepere küla, 21. ja 26. V 1956 (2 leiukohta); Viljandi linna põhjaserva lähedalt, 31. V. 1956.

**8. Eucypris ornata (O. F. Müller) 1776. ㅇ.

Väga harva esinev, kuid võrdlemisi arvukas liik. Leitud ainult selgeveelistest taimestikuga temporaarseist veekogudest. Kevadvorm. Leiukohad: Langenurme lähedalt (Pärnu-Jaagupi raj.), 28. V 1957; ca 2 km Viljandi linna loodeservast, Tomuski pere lähedalt, 28. V 1956.

\section{Eucypris virens (Jurine) 1820 (= Cypris ornata Fischer} 1854). 우우.

Keskmise sageduse ja keskmise arvukusega liik, konstateeritud ainult taimestikuga temporaarseis väikeveekogudes. Kevadvorm. Leiukohad: Puhtulaid, 20. V 1957; Tuhu soo lääneserv (Lihula raj.), 28. V 1957; Vorbuse,

\footnotetext{
*-ga märgitud kuupäeva proovides esines ainult kas antud liigi surnud isendeid vôi tühje kodasid.
} 
8. VI 1956 ja Variku, 2. ja 22. V 1957 (2 leiukohta) (mõlemad Tartu raj.); Saarepere küla, 21.-23. V 1956 (5 leiukohta); Sinialliku lähedalt (Viljandi raj.), 30. VI 1956.

*10. Eucypris fuscata (Jurine) 1820. 우.

Harva esinev vähese arvukusega liik. Senini püütud ainult taimestikurikastest temporaarsetest lompidest. Leiukohad: Kalli lähedalt (Lihula raj.), 27. V 1957; Saarepere küla, 14. IX 1957; Sinialliku lähedalt, 30. VI 1956.

*11. Eucypris affinis (Fischer) 1851. 웅․

Võrdlemisi sage keskmise arvukusega kevadsuvine vorm. Eelistab elutseda taimestikulistes temporaarsetes veekogudes. Harva leitud ka permanentseist väikeveekogudest ning ühel juhul järve madalaveelisest taimestikurikkast litoraalist (Pulli järv, 14. VII 1957). Rohkem kui 20 leiukohta; levinud üle kogu mandri.

*12. Eucypris lilljeborgi (G. W. Müller) 1900 ?. 우오.

Harva esinev. Kogutud lombist Emajõe luhalt Luutsna jõe suubumiskoha lähedalt (Tartu raj.), 2. V 1957. (Määratud formaliinis fikseeritud, söövitunud kodadega materjali järgi.)

\section{Eucypris lutaria (Koch) 1838 (= Cypris Jurinii}

Fischer 1854). 우오.

Keskmise sagedusega ja tihti suure arvukusega liik. Elutseb taimestikuga mudase põhjaga temporaarseis veekogudes (lombid, kraavinired). Kevadise generatsiooni kõrval esineb ka sügisene. Leiukohad: Emajõe luht Luutsna jōe suubumiskoha lähedal, 5. V 1957; Variku, 2. ja 22. V 1957 (2 leiukohta); Saarepere küla, 21. V 1956 ja 14. IX 1957 (5 leiukohta); Viljandi linna põhjaserv, 28. V 1956; Mustla-Kuressaare (Viljandi raj.), 1. XI 1957.

\section{*14. Dolerocypris fasciata (O. F. Müller) 1776. 우.}

Vàga sage liik. Elutseb eelkõige järvede litoraalis, harvemini taimestikurikastes väikeveekogudes (ka temporaarsetes). Harvadel juhtudel leitud aeglaselt voolavaist ojadest. Talub nähtavasti ka vee nõrka soolsust (leid Siiksaare lahest, Orissaare raj., 22. VII 1956). Arvukus enamasti keskmine. Esineb ainult suveperioodil (mai lõpust septembri keskpaigani). Ligi 50 leiukohta; levinud üle kogu mandriala, leitud ka Saaremaalt.

\section{Heterocypris incongruens (Ramdohr) 1808}

(= Cypris fusca Fischer 1854). 우 .

Võrdlemisi sage liik. Elutseb valdavalt temporaarseis väikeveekogudes, sealhulgas (enamasti ainsa karpvähilisena) tihti täiesti taimestikutá savise põhjaga lompides ja kraavides; leidub ka allikaveekogudes. Liik on peaaegu alati arvukas. Rohkem kui 20 leiukohta; levinud üle kogu mandriosa.

\section{*16. Ilyodromus olivaceus (Brady et Norman) 1889. 우 ㅇ․}

Selle liigi ainsateks leiukohtadeks Eestis on seni olnud rannalähedased järved Suur-Silm ja Väike-Silm Kingissepa rajoonis (proovipüük 27. VII 1956). Mõlemad nimetatud leiud madalatest suhteliselt sooja veega rannikujärvedest on huvipakkuvad, kuna kirjanduse andmeil (Schäfer, 1936; Klie, 1925 ја 1938; Бронштейн, 1947) on liik tüüpiline krenobiont. 
Kaufmann (1900) Sveitsis ja Sars (1928) Norras on konstateerinud seda liiki madalates kraavides. ${ }^{3}$

*17. Herpetocypris reptans (Baird) 1835. ㅇ.

Seni harva leitud keskmise arvukusega liik. Leiukohad: lomp Rammu saarel (Harju raj., tõenäoliselt riimveeline veekogu), 1. VIII 1937 kogutud proovist; Leevaku pais Võhandu jõel (Räpina raj.), 23. V 1957; Rõuge Liinjärve litoraal (Võru raj.), 19. VII 1957.

*18. Cypridopsis aculeata (Costa) 1847. 우 우.

Konstateeritud meil ainult nõrgalt soolases vees (isoleeritud merelaht, merega ühenduses olev rannikujärv, merre suubuva oja alamjooks), kus ta näib olevat võrdlemisi tavaline. Liigi arvukus on keskmine. Leiukohad: Käina laht (Hiiumaa raj.), 5. VIII 1956; Allikoja (Kingissepa raj.), 26. VII 1956; Käomardi laht (Lihula raj.), 1. VIII 1957.

19. Cypridopsis vidua (O. F. Müller) 1776. 우 우.

Uks meie kõige tavalisemaid karpvähilisi. Ubikvist: elutseb nii temporaarsetes veekogudes kui ka permanentsetes väikeveekogudes, järvede litoraalis ja profundaalis, jõgedes-ojades, allikaveekogudes, samuti riimvees, olles kõikjal tavaline. Eriti sage järvede litoraalis, kus esineb väga mitmesugustes biotoopides, muuhulgas ka hõreda taimestikuga liivastel aladel. Tihti arvukas. Teada ligikaudu 100 leiukohta; levinud üle kogu mandriosa ja Saaremaa.

*20. Cypridopsis obesa Brady et Robertson 1869. 우 ㅇ․

Keskmise sagedusega, nähtavasti lokaalne liik. Elutseb temporaarsetes ja permanentsetes väikeveekogudes ning järvede litoraalis. Arvukus mitmesugune. Leiukohad: Ähijärv (Antsla ja Valga raj.), 21. VII 1957; Vellavere küla lomp (Elva raj.), 8. VII 1957; Selgküla temporaarsed veekogud Sillastu ja Uueselja järv (Haapsalu raj.), 15. VI 1957; Ulemiste järv, 5. ja 6. IX 1957; Änkküla lombid (3 leiukohta), 3. VII 1957 ja Kivijärv ning lodu selle luhal, 2. VII 1957 (mõlemad Jõgeva raj.); Suur-Kirjaku järv (Jõhvi raj.), 15. VIII 1957; kraav endise Saare kõrtsi lähedal (Mustvee raj.), 27. VI 1957; vanajõgi Lavassaare järve lõunakaldả lähedal (Pärnu raj.), 31. VII 1957; turbaauk Emajõe luhal Tartu linna loodeserval, 5. VII 1957.

*21. Cypridopsis parva G. W. Müller 1900 ?.

Leiukoht: Kudani järve kaldavöönd (Haapsalu raj.), 1. VIII 1956 (1 eks., ㅇ juv.).

*22. Cypridopsis orientalis Bronštein 1927.

Väga haruldane liik; ainult üks leiukoht - temporaarne niidulomp Rannakülas (Elva raj.), 9. VIII 1956 (1 eks., 우 ad.).

*23. Potamocypris villosa (Jurine) 1820. ㅇ.

Senini ainult üks leiukoht - kevadistest allikatest toituv mudase põhjaga loopealne lomp Täätsi lähedal (Orissaare raj.), 20. VII 1956.

*24. Potamocypris variegata (Brady et Norman) 1889.

Ainus eksemplar Kärla jõest (Kingissepa raj.) samasuvise jõevähi maost, 10. VIII 1954.

3 1958. a. suvel leidis käesoleva artikli autor Ilyodromus olivaceus't ka mõnedest Eesti allikatest, 


\section{*25. Cyclocypris ovum (Jurine) 1820. 수 $\hat{\delta}$, 우.}

Kōige sagedamini esinevaid karpvähilisi Eesti veekogudes. Ubikvist: elutseb temporaarsetes veekogudes ja permanentsetes väikeveekogudes, järvede litoraalis ja profundaalis, jõgedes-ojades, allikaveekogudes, samuti riimvees; on kôikjal tavaline. Arvukus ei ole enamikul juhtudel kõrge. Rohkem kui 60 leiukohta; levinud üle kogu territooriumi.

\section{*26. Cyclocypris laevis (O. F. Müller) 1875. 화 $\hat{\delta}, ㅇ ㅜ$.}

Nagu eelminegi - meie kõige tavalisemaid ostrakoode. Samuti ubikvist, kuid $C$. ovum'ist mõnevõrra väiksema kohanemisvõimega (esinemist riimvees pole meil senini täheldatud). Keskmise arvukusega. Ligikaudu 80 leiukohta; levinud üle kogu territooriumi.

*27. Cyclocypris globosa (G. O. Sars) 1863. 하, $\hat{\text {, }}$ 우.

Harva esinev liik, konstateeritud väikesel kuni keskmisel arvukusel. Leiukohad: lomp Abja-Paluoja alevi lääneserval (Abja raj.), 27. V 1957; temporaarsed lombid Meelva külas (Räpina raj.), 22. X 1957 (2 leiukohta).

\section{*28. Cypria exsculpta (Fischer) 1855. ㅎํ $\hat{o}$, 우 ㅇ.}

Liik elutseb eeskätt järvedes, nii litoraalis kui ka profundaalis, ja on võrdlemisi sage. Uksikutel juhtudel leitud ka mittekuivavatest väikeveekogudest ja jõ̃gedest. Arvukus mitmesugune, järvedes sageli kõrge. Seni teada 18 leiukohta; levinud üle kogu mandri, esineb ka Saaremaal.

\section{Cypria ophthalmica (Jurine) 1820 (= Cypris elegantula}

\section{Fischer 1854). 소 $\hat{o}$, 우.}

Keskmise sagedusega liik. Elutseb järvedes, permanentsetes väikeveekogudes ja allikaveekogudes. Püütud mitmesugusel hulgal; kõige suurema arvukusega konstateeritud talvistes proovides (TRU Botaanikaaia tiigis 10. III 1957 ja Pangodi järve litoraalis 13. I 1958). Seni teada 16 leiukohta; levinud üle kogu mandriala.

\section{**30. Physocypria kliei Schäfer 1934.}

Haruldane. Ainus leiukoht - Noodasjärve litoraal (Võru raj.), 18. VII 1957 (2 eks., 우 우 ad.).

\section{*31. Candona candida (O. F. Müller) 1785. ㅊㅇ $\hat{\delta}$ 우.}

Sage ja tihti arvukalt esinev liik. Elutseb ubikvistina taimestikurikastes väikeveekogudes (nii temporaarsetes kui ka permanentsetes), järvedes, allikaveekogudes; leitud ka riimveest. Külmalembene. Ligi 40 leiukohta mandril ja Saaremaal.

\section{*32. Candona weltneri Hartwig 1898. 소 $\hat{\circ}$, 우.}

Leitud senini ainult järvedest (nii litoraalist kui profundaalist), kus ta nähtavasti pole haruldane. Leiukohad: Pangodi järv (Elva raj.), 13. I 1958; Kahala järv (Harju raj.), 15. VI 1957; Saadjärv, 17. I 1958*; Nõuni järv (Otepää raj.), 13. I 1958.

\section{*33. Candona sarsi Hartwig $1899(=$ C. hartwigi G. W. Müller 1900). 하 ㅎ․, 우 ㅇ․}

Vōrdlemisi harva esinev liik. Kõik senised leiud Eestis pärinevad järvede litoraalist ja sublitoraalist. Leiukohad: Verevi järv (Elva raj.), 8. VII 1957; Prossa järv ja Pikkjärv (569) (mõlemad Jõgeva raj.), 25. VI 1957; Karula-Pikkjärv (Valga raj.), 23. VII 1957, 
**34. Candona lobipes Hartwig 1900.

Ainus leiukoht - Murati järve mudane taimestikurikas litoraal (Vastseliina raj.), 14. VII 1957 (1 eks., 우).

*35. Candona parallela G. W. Müller 1900. ㅇ.

Võrdlemisi sage, kuid enamasti väikese arvukusega liik. Elutseb peamiselt temporaarsetes veekogudes ja järvede litoraalis; leitud ka allikaveekogudest ja riimveest. 14 leiukohta mandril ja Hiiumaal. Tavalise var. typica kõrval konstateeritud ühes veekogus (Nõuni järv, 13. I 1958) ka var. albicans Brady.

*36. Candona insculpta G. W. Müller 1900. ㅊ s, 우.

Harva esinev liik. Püütud väheste eksemplaridena kahe järve litoraalist: Ähijärv, 21. VII 1957; Karula-Pikkjärv, 23. VII 1957.

*37. Candona compressa (Koch) 1837. ㅅㅎㅇ, 우 ㅇ.

Harva leitud vähese arvukusega liik. Senised leiud pärinevad järvede litoraalist ja sublitoraalist. Leiukohad: Ruhja järv (Abja raj.), 27. VII 1957; Pikkjärv (569) ja Prossa järv, 25. VI 1957; Murati järv, 14. VII 1957.

38. Candona pratensis Hartwig 1901 (= Cypris compressa Fischer 1854). 소오, 우 ㅇ․

Võrdlemisi sage liik. Elutseb valdavalt temporaarseis veekogudes, esineb aga ka permanentseis väikeveekogudes. Arvukus mitmesugune. Leiukohad: Rannaküla (Elva raj.), 26. V 1957; Selgküla (Haapsalu rāj.), 16. VI 1957; Pupastvere küla (Jõgeva raj.), 4. VII 1956; Räpina alevi lähedalt, 22. V 1957; Saarepere küla, 21.-26. V 1956 ja 14. IX 1957 (10 leiukohta); Uueveski org Viljandis, 28. V 1957; Plaksi küla (Võru raj.), 17. VII 1957.

*39. Candona crispata Klie 1926.

Haruldane. Ainus leiukoht - lomp Räpina alevi lähedal, 22. V 1957 (1 eks., $\hat{o}$ ).

40. Candona fabaeformis (Fischer) 1851. ㅎ․ 우우 ㅇ.

Mitte haruldane, kuid väikese arvukusega liik. Elutseb järvedes (nii litoraalis kui ka profundaalis). Leiukohad: Pangodi järv, 7 . VII $1957^{*}$ ja 13. I 1958*; Kivijärv, 3. VII 1957; Pikkjärv (569), 25. VI 1957; Prossa järv, 25. VI 1957; Nõuni järv, 6. VII $1957^{*}$ ja 13. I 1958*.

*41. Candona holzkampfi Hartwig 1900.

Ainus leiukoht - lomp Räpina alevi lähedal, 22. V 1957 (1 eks., ô ).

42. Candona acuminata (Fischer) 1851

Harva esinev liik. Leiukohad: Nõuni järve mudane litoraal, 13. I 1958* (1 eks., ô ); temporaarne lomp soisel niidul Saarepere külas, 14. IX 1957 (3 eks., to $\hat{o})$.

\section{*43. Candona protzi Hartwig 1898. ㅎํ ô, 우 우.}

Leitud järvedest, kus esineb nii litoraali kui ka profundaali alal; keskmise sagedusega, arvukus mitmesugune. Leiukohad: Karijärv, 9. VII 1957*, Pangodi järv, 13. I 1958, Viisjaagu ja Vissi järv ning kanal nende vahel (Elva raj.), 17. XII 1957; Prossa järv, 25. VI 1957; Saadjärv, 17. I 1958*; Nõuni järv, 13. I 1958. 
*44. Candona caudata Kaufmann 1900. ㅇ.

Harva esinev liik; elutseb nähtavasti üksnes suuremates järvedes. Leiukohad: Võrtsjärve mudane lõunasopp (1,7 m sügavuselt), III 1958*; Nõuni järve mudane litoraal (2,1 m sügavuselt), 6. VII 1957*.

*45. Candonopsis kingsleii (Brady et Robertson) 1870. 소 수 우 ㅇ․ Harva esinev liik; seni ainult 2 leidu: Ubajärve liivase-mudase põhjaga ning taimestikuga litoraalist (Antsla raj.), 22. VII 1957; Kiruvere järvest (Kose raj.), 18. IX 1956.

\section{Darwinulidae}

*46. Darwinula stevensoni (Brady et Robertson) 1870.

Võrdlemisi haruldane, järvedes ja jõgedes. Talub ka nõrka soolsust. Enamasti vähearvukas, erandina arvukas paiguti Võrtsjärves. Leiukohad: Mäeküla järve litoraal (Abja raj.), 28. VII 1957*; Prest-Wiek (Haapsalu raj., Vormsi), 30. VII 1956; Vartsi jōgi meresuudme lähedal (Kingissepa raj.), 26. VII 1956*; Võrtsjärv (litoraal ja profundaal), III 1958.

\section{Cytheridae}

\section{*47. Cytherissa lacustris G. O. Sars 1863.}

Harva esinev liik. Elutseb nähtavasti ainult suuremates järvedes, kus asustab sublitoraali ja profundaali. Leiukohad: Võrtsjärv (mitmesugustest biotoopidest), III 1958*; Saadjärv (6 m sügavuselt), 17. I 1958*; Nõuni järve mudaselt põhjalt (2,1 ja $8,2 \mathrm{~m}$ sügavuselt), 6. VII 1957 ja 13 . I 1958*.

*48. Limnocythere inopinata (Baird) 1843. 우 오.

Võrdlemisi sage, kuid enamasti väikese arvukusega liik. Elutseb järvedes ja jõgedes, talub hästi ka nõrgalt soolast vett. Seni 15 leiukohta mandrilt, Saaremaalt, Hiiumaalt ja Vormsist.

*49. Limnocythere sancti-patricii Brady et Robertson 1869. 하 of, 우

Liiki esineb harva ja nähtavasti üksnes suuremates järvedes. Leiukohad: Saadjärve profundaalist $6 \mathrm{~m}$ sügavuselt, 17. I 1958* (proovis massiliselt tühje kodasid); Nõuni järve mudase põhjaga sublitoraalist $2,1 \mathrm{~m}$ ja profundaalist $6 \mathrm{~m}$ sügavuselt, 13. I 1958*.

*50. Metacypris cordata Brady et Robertson 1870. 수웅 우.

Liiki on Eestis seni leitud ainult järvede litoraalist ja sublitoraalist. Nähtavasti võrdlemisi sage, kuid raskesti leitav oma väikeste mõōtmete tõttu. Arvukus keskmine kuni väike. Leiukohad: Võrtsjärv, III 1958*; Pangodi järv, 13. I 1958*; Toatse järv (Haapsalu raj.), 7. VIII 1956; KurtnaHaugjärv (Jõhvi raj.), 15. VIII 1957; Pühajärv, 3. VI 1957; Murati järv, 14. VII 1957. 


\section{KARPVAHILISTE FAUNA KOOSSEISUST EESTI NSV ERI TUUPI VEEKOGUDES}

1. Temporaarsed veekogud (mitmesugused ajutised, suvel kuivavad lombid, kraavikesed, soonetised, lodud, karjäärid jne.). Nende veekogude karpvähiliste faunale on iseloomulik eelkỗige liigilise koosseisu rikkus (senini konstateeritud 24 liiki) ja eutsöönsete (= karakteersete) liikide domineerimine. Viimased moodustavad ca $55 \%$ kõigist leitud liikidest. Sealjuures väärib erilist tähelepanu terve rea spetsiifiliste eutsöönsete (s. t. ainult vastavas veekogu tüübis elutsevate) liikide esinemine, kes kuuluvad eeskätt perekonda Eucypris, näit. Eucypris virens, E. fuscata, E. lutaria, E. ornata, Cyprois marginata, tõenäoliselt ka Eucypris lilljeborgi ja Cypridopsis orientalis. Spetsiifilistele liikidele on arengutsükli läbimiseks kuivamine obligatoorne. Samuti on märkimisväärne preferentsete eutsöönsete (s. t. antud tüüpi veekogudes eelistavalt elutsevate) karpvähiliste arv. Viimaste hulka kuuluvaks tuleks lugeda Eucypris crassa, E. affinis, Heterocypris incongruens, Candona pratensis ning tōenäoliselt ka Cyclocypris globosa ja Cypris pubera. Valdav enamik eutsöönsetest liikidest kuulub monotsükliliste kevadiste ja varasuviste vormide hulka, kellest ainult harukordadel mõned võivad anda veel teise generatsiooni aastas (Cypris pubera, Eucypris crassa, E. ornata, E. virens, E. affinis, Candona pratensis jt.) Silma paistab perekond Candona liikide vähesus eutsööni hulgas (ainult üks liik $-C$. pratensis). Tühhotsöönsetest (= fakultatiivsetest) liikidest on esindatud kōik viis ubikvisti - Notodromas monacha, Cypridopsis vidua, Cyclocypris ovum, C. laevis ja Candona candida ning rida teisi kuivamist taluvaid vorme (Ilyocypris gibba, I. biplicata, Dolerocypris fasciata, Cypridopsis obesa, Candona parallela, C. acuminata).

2. Permanentsed väikeveekogud (mittekuivavad lombid, tiigid, karjäärid, linaleod, vanajõed jne., välja arvatud ilmsed allikaveekogud). Siinne ostrakoodide fauna on märgatavalt liigivaesem temporaarsete veekogude omast (senini kindlaks tehtud 16 liiki). Väga iseloomulik permanentsetele väikeveekogudele on eutsöönsete karpvähiliste vähesus: täielikult puuduvad spetsiifilised liigid, kuna ainus leitud preferentne eutsöönne liik Potamocypris villosa on haruldane. Permanentsete väikeveekogude ostrakoodide fauna koosneb seega praktiliselt tervenisti tühhotsöönsetest vormidest, kelle hulgas esinevad kõik viis eespool loetletud ubikvisti (sageli kōrge arvukusega), rida temporaarsete veekogude preferentseid eutsöönseid liike (Cypris pubera, Eucypris crassa, E. affinis, Candona pratensis), mōned järvede litoraalile karakteersed karpvähilised (Dolerocypris fasciata, Cypria exsculpta, $C$. ophthalmica), samuti vorme, kes esinevad enam-vähem ühesuguse sageduse ja arvukusega mitmes veekogu tüübis (näit. Cypridopsis obesa).

3. Järved. Järvede puhul osutub otstarbekohaseks käsitleda litoraali ja sublitoraali ala lahus profundaalist.

Litoraa $1 \mathrm{i}$ ja sublit or a $1 \mathrm{i}$ karpvähiliste faunat iseloomustab, vastavalt biotoopide mitmekesisusele, suur liigirikkus: senini on siit leitud 32. liiki - märgatavalt rohkem kui kusagilt mujalt. Puuduvad spetsiifilised eutsöönsed vormid, kuid seevastu esineb rikkalikult preferentseid eutsöönseid (senini konstateeritud 10 liiki), kelle hulgas on eriti silmapaistval kohal perek. Candona esindajad: C. protzi, C. weltneri, C. sarsi, C. insculpta, C. compressa, C. caudata. Väga karakteersed karpvähilised meie järvede litoraalile on ka Dolerocypris fasciata, Cypria exsculpta, C. ophthalmica ja Metacypris cordata. Silmapaistvalt suur on leitud tüh- 
hotsöönsete liikide arv - 21. Viimaste hulgas on esindatud kõik ubikvistid (esinevad siin sageli arvukalt), rida väikeveekogudega ühiseid liike (näit. Cypridopsis obesa, Candona parallela, C. acuminata), samuti (eriti sublitoraali alal) kõik järvede profundaali karakterliigid.

Profundaali ala karpvähiliste faunat iseloomustab liigivaesus: senini on siin kindlaks tehtud ainult 11 liigi esinemine. Spetsiifilised eutsöönsed karpvähilised järvede profundaalis nähtavasti puuduvad; preferentseid eutsöönseid liike on konstateeritud kolm - Cytherissa lacustris, Limnocythere sancti-patricii ja Darwinula stevensoni. Nendest kaks esimest on iseloomulikud just suurematele järvedele. Ka leitud tühhotsöönsete liikide arv (8) ei ole suur. Viimaste hulgas esineb järvede litoraali preferentseid eutsöönseid vorme (Cypria exsculpta. Candona protzi), ubikviste (nendest puudub Notodromas monacha) jm.

Spetsiifilisteks karpvähilisteks järvedele (arvestades koos litoraali ja profundaali ala) võib pidada kaht liiki - Cytherissa lacustris ja Limnocythere sancti-patricii. Järvede eutsöönsed ostrakoodiliigid kuuluvad eelkõige perekonda Candona ja sugukonda Cytheridae.

4. Jõed ja ojad. Mitteküllaldase uurituse tõttu ei saa jõgede-ojade ostrakoodide faunale siinkohal anda veel piisavat iseloomustust. Tähelepanu väärivate asjaoludena võib siiski ära märkida liigilise koosseisu vaesust (konstateeritud 10 liiki) ja eutsöönsete liikide vähesust (senini kindlaks tehtud ainult ühe preferentse eutsöönse liigi - Potamocypris variegata - esinemine). Tühhotsöönsete liikide hulgas on tähtsal kohal ubikvistid (leitud 4 liiki) ja järvede eutsöönsed liigid (Dolerocypris fasciata, Cypria exsculpta, Darwinula stevensoni).

5. Allikaveekogud. Ka seda tüüpi veekogude karpvähiliste faunale näib liigivaesus iseloomulik olevat. Senini on meie allikais konstateeritud ainult 10 liiki karpvähilisi. Eutsöönseid ostrakoode pole Eesti allikaveekogudest seniste uurimuste andmeil üldse teada, kuid arvestades kirjanduse andmeid ja veel mitteküllaldast materjali hulka võib oletada, et neid siiski esineb. ${ }^{4}$ Tühhotsöönsete liikide rühm koosneb peaaegu eranditult ubikvistidest (konstateeritud kõik 5 liiki) ja kas külmalembestest või eurütermsetest väikeveekogude preferentsetest eutsöönsetest vormidest (näit. Heterocypris incongruens, Cyclocypris globosa, Candona pratensis, Cypris pubera).

6. Riimveekogud (mere mõju all olevad rannikujärved, merre suubuvate jōgede suudmepiirkonnad, eraldunud merelahed ja -sopid). Nende veekogude karpvähiliste fauna on samuti liigivaene (teada 9 liiki). Spetsiifiliseks eutsöönseks ostrakoodiks meie riimveekogudele võib senistel andmetel pidada Cypridopsis aculeata't, kuna preferentseid eutsöönseid vorme pole konstateeritud. Tühhotsöönsete liikide hulgas on tähtsal kohal ubikvistid - Notodromas monacha, Cypridopsis vidua, Cyclocypris ovum ja Candona candida; nende kõrval esineb aga ka teisi nõrka soolsust taluvaid mageveelisi liike (Herpetocypris reptans, Darwinula stevensoni, Limnocythere inopinata).

Võrreldes Eesti eri tüüpi veekogude karpvähilisi faunistilise suguluse leidmise eesmärgil ilmneb, et temporaarsetel veekogudel on kõige rohkem $(46 \%)$ ühiseid liike permanentsete väikeveekogudega ja viimastel omakorda temporaarsete veekogudega (69\%). Nii temporaarsetel veekogudel kui ka permanentsetel väikeveekogudel on rohkesti ühiseid karp-

4 1958, a. suvel leidis autor eutsöönseid karp̣vähilisi reast allikaist Põhja-Eestis ja läänesaartel. 
vähiliste liike veel järvede litoraaliga (vastavalt 42 ja $62 \%$ ) ning allikaveekogudega (vastavalt 37,5 ja $50 \%$ ), väga vähe aga järvede profundaaliga ja riimveekogudega (ühisteks liikideks osutuvad siin üksnes ubikvistid). Järvede litoraalil ja sublitoraalil on ühiseid liike kõigi teist tüüpi veekogudega peaaegu võrdselt. Kõik järvede profundaalist leitud karpvähilised esinevad ka litoraalis ja sublitoraalis. Ubikvistid on järvede profundaalil ainsateks ühisteks liikideks peale temporaarsete veekogude ja permanentsete väikeveekogude ka allikaveekogudega. Jōgedeojade karpvähiliste faunal on kõige rohkem $(90 \%)$ ühiseid liike järvede litoraaliga. Enamik allikaveekogudes konstateeritud ostrakoodidest elutseb ka temporaarsetes veekogudes ja permanentsetes väikeveekogudes ning järvede litoraalis (ühiseid liike vastavalt 90,80 ja $70 \%$ ). Riimveekogudel on mitteubikvistlikke ühiseid liike eelkõige järvede litoraaliga ja jõgedega-ojadega.

\title{
KIR J A N D US
}

Б р оншт ей н 3. С., 1947. Ostracoda пресных вод. Фауна СССР, Ракообразные, т. II, вып. І. Москва-Ленинград.

Eichwald, E., 1852. Dritter Nachtrag zur Infusorienkunde Russlands. Bulletin de la Société Impériale des Naturalistes de Moscou, tome XXV. Moscou.

Fischer, S., 1854. Abhandlung über das Genus Cypris, und dessen in der Umgebung von St. Petersburg und von Fall bei Reval vorkommenden Arten. Mémoires présentés à l'Académie Impériale des Sciences de St.-Pétersbourg par divers savants, tome VII. Saint-Pétersbourg.

K a u f mann, A., 1900. Cypriden und Darwinuliden der Schweiz. Revue Suisse de Zooloogie. Annales de la Société Zoologique Suisse et du Musee d'Histoire Naturelle de Genève, tome VIII. Genève.

K 1 i e, W., 1925. Entomostraken aus Quellen. Archiv für Hydrobiologie, Bd. XVI, Heft 2. Stuttgart.

K1 i e, W., 1938. Ostracoda, Muschelkrebse. Die Tierwelt Deutschlands und der angrenzenden Meeresteile, 34. Teil, Krebstiere oder Crustacea III. Jena.

Riikoja, H., 1934. Eesti järvede nimestik. Andmed Eesti ala järvede uurimiseks, nr. 19. Tartu.

S a r s, G. O., 1928. Ostracoda. An Account of the Crustacea of Norway, vol. IX. Bergen.

S chneider, G., 1908. Der Obersee bei Reval. Berlin.

S chäfer, H., 1936. Copepoden und Ostracoden aus schlesischen Gewässern. Sonderabdruck aus: Abhandlungen der Naturforschenden Gesellschaft zu Görlitz, Bd. XXXII, Heft 3 .

Eesti NSV Teaduste Akadeemia

Zooloogia ja Botaanika Instituut

Saabus toimetusse

21. VI 1958

\section{ДАННЫЕ О ФАУНЕ РАКУШКОВЫХ РАЧКОВ (OSTRACODA) ПІРЕСНЫХ ВОД ЭСТОНИИ}

\author{
А. А. Ярвекюльг, \\ нандидат биологических наук
}

\section{Резюме}

В статье приводятся данные о фауне ракушковых рачков пресных вод Эстонии, оставшейся до настоящего времени почти совершенно неизученной. С 1956 по 1958 гг. автором разработано 350 проб остракод из 290 разных водоемов Эстонин. Дается список ракушковых рачков, установленных автором к настоящему времени для пресных вод Эстонии, который состоит из 50 видов. Одновременно представляются данные о распространении и биологии этих видов. Для более редких видов дается перечень местонахождений. В списке звездочкой отмечены виды, являющиеся новыми для фауны Эстонин, двумя звездочками - новые виды для фауны СССР. 
Во второй части статьи рассматривается состав фауны ракушковых рачков в разных типах водоемов Әстонии. Для темпорарных водоемов, как выясняется, очень характерно богатство видового состава и доминированне эвценных (Е характерных) видов, причем встречается целый ряд специфических видов (особенно из рода Eucypris), обнтающих только в этом типе водоемов (Eucypris virens, E. fuscata, E. lutaria, E. ornata, Cyprois marginata и др.).

Видовой состав фауны остракод перманентных (= непересыхающих) мелких водоемов значительно беднее и состонт практически полностью из тихоценных (=факультативных) форм, среди которых важнейшее место занимают убиквисты, и преферентно-эвценные виды темпорарных водоемов (отчасти и преферентно-эвценные виды литорали озер).

Богаче всего видовой состав фауны ракушковых рачков в литорали и сублиторали озер (до сих пор найдено 32 вида). Специфических форм здесь не установлено, но имеется большое количество преферентно-эвценных, в первую очередь из рода Candona. Видовой состав фауны остракод профундали озер оказывается бедным. Характерными видами для профундали более крупных озер можно считать Cytherissa lacustris, Limnocythere sancti-patricii и Darwinula stevensoni. Из них два первых в то же время являются, по-видимому, специфическими остракодами для озер.

Фауна ракушковых рачков рек и ручьев изучена пока еще слабо. Бедным оказывается видовой состав фауны остракод как в источниковых, так и в солоноватых водоемах, причем для первых специфические виды остракод пока еще неизвестны. ${ }^{1}$ Фауна здесь состоит, с одной стороны, из убиквистов и, с другой стороны, из холоднолюбивых и эвритермичных преферентно-эвценных форм мелких водоемов. В составе фауны ракушковых рачков солоноватых водоемов на важном месте стоят убиквисты, Специфической формой для таких водоемов оказывается, по-видимому, Cypridopsis aculeata.

Общих видов больше всего имеют: темпорарные водоемы - с перманентными мелкими водоемами, а последние, в свою очередь, с темпорарными водоемами; профундаль озер, реки-ручьи и солоноватые водоемы - с литоралью и сублнторалью озер; источниковые водоемы - с темпорарными водоемами и перманентными мелкими водоемами. Литораль и сублитораль озер имеют почти одинаковое количество общих видов со всеми другими типами водоемов.

Ннститут зоологии и ботаники

Академии наук Эстонской ССР

Поступила в редакцию

21 VI 1958

\section{ANGABEN UBER DIE OSTRACODEN-FAUNA DES SUSSWASSERS ESTLANDS}

\section{A. Järvekülg}

\section{Zusammenfassung}

Im Artikel werden Angaben über die Ostracoden-Fauna des Süsswassers Estlands gebracht, die bis zur gegenwärtigen Zeit beinahe völlig unerforscht war. Der Autor hat in den Jahren 1956-1958 350 Proben des Ostracoden-Materials von 290 verschiedenen Gewässern Estlands bearbeitet. Es wird auch ein Verzeichnis der bis jetzt vom Autor im Süsswasser Estlands festgestellten Ostracoden gegeben, das 50 Arten enthält. Gleichzeitig werden Angaben über Verbreitung und Biologie der festgestellten Arten gegeben, wobei für weniger verbreitete Arten auch ihre Fundorte angeführt werden. Im Verzeichnis sind die für die Fauna von Estland neuen Arten mit einem Sternchen, die für die Fauna der Sowjetunion neuen Arten mit 2 Sternchen bezeichnet.

Im zweiten Teil des Artikels wird die Zusammensetzung der Ostracoden-Fauna in den verschiedenen Gewässertypen Estlands betrachtet. Für die temporären Gewässer ist der grosse Reichtum der Artenzusammensetzung und das Dominieren der eucönen (charakteristischen) Arten sehr bezeichnend, wobei eine Reihe von spezifischen, nur in diesem Gewässertyp auftretenden Formen (Eucypris virens, E. fuscata, E. lutaria, E. ornata, Cyprois marginata u. a.) beobachtet wurde.

Die Ostracoden-Fauna der permanenten Kleingewässer ist entschieden artenarmer als die der temporären Gewässer; sie besteht fast ganz aus tychocönen (fakultativen) Formen, worunter Ubiquisten, auch präferente eucöne Arten der temporären Gewässer, zum Teil auch der Seelitorale, eine wichtige Stellung einnehmen.

Am artenreichsten ist die Ostracoden-Fauna im Litoral und Sublitoral der Seen vertreten (bis jetzt 32 Arten konstatiert). Spezifische Ostracodenarten sind hier nicht gefunden worden, doch wurde eine grosse Anzahl präferenter eucöner Formen beob-

1 Такие виды были найдены автором в ряде источников Эстонии летом 1958 г. 
achtet, in erster Linie von der Gattung Candona. Die Ostracoden-Fauna des Profundals der Seen ist recht artenarm. Als Charakterarten des Profundals der grösseren Seen können Cytherissa lacustris, Limnocythere sancti-patricii und Darwinula stevensoni bezeichnet werden, von denen die zwei ersten Arten gleichzeitig auch scheinbar zu den spezifíschen Seeformen gehören.

Die Ostracoden-Fauna der Flüsse und Bäche ist bis heute sehr wenig erforscht. Die Ostracoden-Fauna der Quellen, sowie auch des Brackwassers ist im allgemeinen recht artenarm. Im Laufe der bis jetzt durchgeführten Forschungsarbeiten ist es nicht gelungen, in den Quellgewässern Estlands das Auftreten von spezifischen Ostracodenarten festzustellen. ${ }^{1}$ Die Fauna der Quellen wird von Ubiquisten, kälteliebenden und eurythermen präferenten eucönen Formen der Kleingewässer gebildet. Für die Ostracoden-Fauna des Brackwassers sind Ubiquisten von Wichtigkeit; für diesen Gewässertyp ist Cypridopsis aculeata scheinbar spezifisch.

Die temporären Gewässer besitzen am meisten gemeinsame Arten mit den permanenten Kleingewässern, die letzteren ihrerseits mit den-temporären Gewässern; das Profundal der Seen, Flüsse und Bäche, sowie das Brackwasser - mit dem Litoral und Sublitoral der Seen; die Quellen - mit den temporären und permanenten Kleingewässern. Das Litoral und Sublitoral der Seen besitzen gemeinsame Arten mit allen Gewässern, und zwar in nahezu gleichem Masse.

Institut für Zoologie und Botanik

der Akademie der Wissenschaften der Estnischen SSR

Eingegangen

am 21. Juni 1958

1 Entsprechende Formen wurden vom Verfasser im Sommer 1958 in einer Anzahl Quellen Estlands gefunden. 